\title{
OBJECTIVE AND SUBJECTIVE DETERMINANTS OF SELF-RATED HEALTH IN CENTRAL AND EASTERN EUROPE: A MULTILEVEL APPROACH
}

\author{
Liubov V. Borisova \\ Department of Sociology, Uppsala Univerisity, Uppsala, Sweden
}

\section{SUMMARY}

Objectives: Determinants of health in Central and Eastern Europe (CEE) have been discussed primarily in relation to the transition of the 1990's and early 2000's, citing lifestyles as the main culprit. This paper tries to draw a bigger picture of the health determinants in CEE in the first decade of the 21 st century. To do so, the two main analytical approaches to health are united in one setting. One of them is based on the definition of health as a personal commodity relying mostly on micro-level subjective data. The other views health as a public commodity analysing objective societal characteristics and health care interventions with often a macro-level perspective. The current study incorporates these different approaches (subjective and objective) in a multi-level setting in CEE.

Methods: The analysis concentrates on health care, social, political, and economic factors as determinants of self-rated health. Multilevel analysis is carried out on a dataset of Life in Transition Survey (LiTS), conducted in 2006 and 2010, pooled cross-sectional data on 46,546 individuals in 27 CEE states. They are accompanied by macro-level data.

Results: The findings demonstrate that a complex mix of determinants influences subjective health in CEE. There are clear differences in the way objective and subjective indicators influence self-rated health. While societal economic prosperity does not influence health, there are strong country-specific differences in the effect of individual prosperity on health.

Conclusions: The study adds to the recent literature on health in CEE by introducing an encompassing systematic approach to analysing health, as no leading cause for self-rated health variation was found. This paper also contributes to research on the determinants of health by fusing objective and subjective determinants in a hierarchical setting. Both subjective and objective determinants matter for health.

Key words: Central and Eastern Europe, subjective health, determinants of health, Life in Transition survey, multilevel analysis

Address for correspondence: Liubov V. Borisova, Department of Sociology, Uppsala Univerisity, Box 624, 75126 Uppsala, Sweden. E-mail: liubov.borisova@soc.uu.se

https://doi.org/10.21101/cejph.a5226

\section{INTRODUCTION}

Central and Eastern Europe (CEE) presents the seemingly never-ending challenge to studying health determinants, an extremely important domain in the field of public health. Evidence of deteriorating health in the CEE region dates back to the 1970's and becomes particularly clear in the 1990's (1). The debates of the causes of this deterioration are still on-going. Among the main factors responsible for this phenomenon, lifestyles are often blamed, particularly, tobacco and alcohol use (2). Most of the authors analyse the data from the 1990's and early 2000's. A recent 2015 study (3) found that while male mortality in Russia is nearly twice as high as in the Czech Republic and Poland, the differences in alcohol consumption between these particular countries are only slight. Hence, alcohol is not the sole explanation (if at all) of all the mortality variation between these countries (3). This finding brings the researchers of modern health issues in CEE back to the beginning.

By now, the countries within the CEE region are highly diverse in terms of economy, political scene, social environment, welfare, and health care. A broad perspective on overall determinants of health in the region is perhaps needed in order to understand the determinants of health of CEE better. This paper sets out to apply a more general and systematic approach to studying health determinants in the countries of CEE and test whether and how the overall common health determinants influence health in the region.

A plenty of research on causes of persisting and widening health gaps worldwide exists nowadays. A big part of this work concentrates on healthcare systems, also accounting for other societal-level characteristics, such as GDP, income inequality, and age structure (4). However, WHO research of the Commission on Social Determinants of Health argues that individual lifestyles and preferences, as well as social and economic conditions people live in impact health of individuals (5). Furthermore, the growing research on subjective well-being of individuals claims that the way people experience their lives is as or even more important than the conditions they live in (6). In health research this finding is confirmed by studies linking health to subjective well-being, satisfaction with life, perceived control over life and trust (1). Hence, both objective (existing) and subjective (experiential) determinants of health, of both societies and individuals need to be addressed. 
Two approaches to studying health can usually be distinguished. One concentrates on the population health and diverse societal, contextual characteristics, with discussions on the role of prosperity and health care on (public) health (7). The second approach mostly studies subjective health at the individual level, and often tries to link it to the individual-level and often subjective (more evaluative) factors. The most common overlap between these two approaches happens when some contextual-level characteristics are included in a multi-level setting when analysing primarily subjective individual health (8). While this happens more and more often, the rationale for 'complicating' the study with different levels is perhaps not fully understood (9). One of the main reasons for using a multi-level setting is the fact that health of an individual and factors that influence it are not independent from the context they exist in $(9,10)$. Hence, contextual effects might add an additional explanation for health differences.

When objective-subjective determinants at the individual level are explored, it becomes clear that the difference between objective-subjective proxies is rarely acknowledged and often researchers use these indicators interchangeably. One of the common practices is the selection of the proxies for income among the available income variables - whether subjective or objective. While this practice of using subjective indicators instead of objective living conditions is understandable, Cummins questions it (11). He finds that unless very poor objective conditions are under scrutiny, the objective and subjective indicators are quite different and often independent from each other. At the same time, subjective indicators should not be discarded, as Ostrove et al. (12) find that after controlling for subjective economic conditions, the objective ones did not matter any longer.

A not-so-new awareness is developing within the public health field, which views the study of health linked solely to the economy as limiting and narrow (13). Yet other studies have also found that health care (4) and political institutional set up (8) are important macro-level factors that determine health as well. Arguably, a different, wider approach to studying health and macro-level effects should be developed (13).

To take the necessary step further, both objective and subjective indicators are included within the same model in a multi-level design. The main goal of this study is therefore twofold: exploring the general health determination process in CEE by bridging the different approaches to analysing health, and studying both objective and subjective determinants of health, as well as their differences, in a multilevel setting.

\section{MATERIALS AND METHODS}

\section{Dataset}

The analysis was carried out using the first two rounds (2006 and 2010) of Life in Transition Survey (LiTS) dataset. It is a unique cross-sectional survey, conducted in the former communist and Soviet countries and Europe in several time-points by the cooperation of the European Bank of Reconstruction and
Development (EBRD) and World Bank (WB). Up to 1,000 faceto-face interviews were carried out in each country using two to three stage equal probability sampling method with some country variations. The data were available for $27 \mathrm{CEE}$ countries* and a total of 58,340 individuals aged 18 and above. As the missing variables were treated list-wise in the analysis, the actual sample was reduced to 46,546 .

The individual-level dataset was complemented with data from several macro-level datasets. Those included the World Health Organisation Health for All Database (WHO HfADb), the World Development Indicators (WDI) from the World Bank and Corruption Perceptions Index (CPI) from Transparency International. All macro-level indicators were added to the LiTS dataset with a one-year lag (i.e. data from 2005 and 2009 for LiTS I and II, respectively). This was done as the macro-level indicators were assumed to require some time to have any effect on people's lives (not to mention people's perceptions), and one year was taken as a minimum lag possible, while other lags tested did not change the results when tested.

\section{Variables}

\section{Dependent Variable}

The main dependent variable in the current analysis was "subjective health", which was measured on a 5-point scale with 1 - "very bad" to 5 - "very good". Since the bias produced by treating a 5-point Likert-scale variable with a normal distribution as continuous is only small (14), and since subjective health in LiTS was measured on a 5-point scale and its distribution was relatively normal, it was treated as a continuous variable.

\section{Independent Variables}

Following the works of Starfield (15), and Dahlgren and Whitehead (10), health determinants were grouped into several domains which were measured at different levels (micro and macro) and two dimensions (objective and subjective). The domains are demographics, social, economic and political indicators, and health care. All indicators used are listed in Table 1.

Demographics included age (in years), sex (binary, $1=$ male) and education (binary variables for lower, secondary and tertiary education), which are all important determinants of health (16, 17). Besides, when analysing subjective health, a way to control for the overall individual's 'positivity level' might be needed, as it potentially influences their responses to any evaluative questions. Therefore, life satisfaction (10-point scale) was included in the analysis. All details on phrasing of questions are provided in Table 2 .

Economic factors are argued to have an association with health both at the macro- and micro-levels. While there is no debate of whether extreme poverty influences health or not (18), general prosperity is a more controversial indicator. I selected two objective economic indicators: employment (binary) and internet access (binary) of the household. As a subjective economic proxy the economic position evaluation on a ten-step ladder was selected, which

\footnotetext{
*List of countries included in the analysis: Albania, Armenia, Azerbaijan, Belarus, Bosnia and Herzegovina, Bulgaria, Croatia, Czech Republic, Estonia, FYROM (Macedonia), Georgia, Hungary, Kazakhstan, Kyrgyzstan, Latvia, Lithuania, Moldova, Montenegro, Poland, Romania, Russia, Serbia, Slovakia, Slovenia, Tajikistan, Ukraine, Uzbekistan.
} 
Table 1. Variables and indicators used for the analysis with LiTS I-II.

\begin{tabular}{|c|c|c|c|c|c|c|}
\hline & Level & Demographics & Economic & Political & Social & Health services \\
\hline \multirow{2}{*}{$\begin{array}{l}\stackrel{0}{0} \\
. \frac{0}{0} \\
\frac{0}{0}\end{array}$} & Micro & $\begin{array}{c}\text { Sex } \\
\text { Age } \\
\text { Education }\end{array}$ & $\begin{array}{l}\text { Employment } \\
\text { Internet access }\end{array}$ & Political activity & $\begin{array}{c}\text { Member } \\
\text { in associations }\end{array}$ & Health services usage \\
\hline & Macro & - & GDP per capita & $\begin{array}{c}\text { Corruption } \\
\text { Perceptions Index }\end{array}$ & $\begin{array}{l}\text { Share of membership in } \\
\text { associations }\end{array}$ & Average length of stay \\
\hline \multirow{2}{*}{ 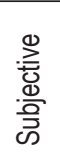 } & Micro & Life satisfaction & Income ladder & $\begin{array}{l}\text { Democracy } \\
\text { preference }\end{array}$ & Trust & $\begin{array}{l}\text { Out-of-pocket payments } \\
\text { in health services }\end{array}$ \\
\hline & Macro & - & - & - & Trust in society & - \\
\hline
\end{tabular}

Table 2. Micro-level indicators used: exact questions wording

\begin{tabular}{|c|c|c|}
\hline Variable & Wording & Scale/Measurement \\
\hline \multicolumn{3}{|l|}{ Dependent variable } \\
\hline Subjective health $(\mathrm{SH})^{\mathrm{S}}$ & How would you assess your health? & 5-point scale with 1 - "very bad" to 5 - "very good" \\
\hline \multicolumn{3}{|l|}{ Demographic variables } \\
\hline $\operatorname{Sex}^{0}$ & Recorded by interviewer & Binary (1 - male) \\
\hline Age $^{0}$ & "How old was ..... at .... last birthday?" & Years \\
\hline Education ${ }^{\circ}$ & $\begin{array}{l}\text { LiTS I: "What is the highest degree you obtained?" LiTS II: } \\
\text { "What is the highest level of education you already com- } \\
\text { pleted?" }\end{array}$ & $\begin{array}{l}1 \text { - no degree/education; } 2 \text { - compulsory school ed; } 3 \text { - sec- } \\
\text { ondary ed; } 4 \text { - proffesional, vocational; } 5 \text { - uni; } 6 \text { - post gradu- } \\
\text { ate. } 3 \text { binary variables created: low education (cate gories } 1 \text {-2), } \\
\text { secondary education (3-4), higher/tertiary education (5-6) }\end{array}$ \\
\hline Life satisfaction ${ }^{s}$ & $\begin{array}{l}\text { "All things considered, how satisfied or dissatisfied are you } \\
\text { with your life as a whole these days?" }\end{array}$ & $\begin{array}{l}\text { 10-point scale, } 1 \text { - "completely dissatisfied", } 10 \text { - "completely } \\
\text { satisfied" }\end{array}$ \\
\hline \multicolumn{3}{|l|}{ Economic variables } \\
\hline Employment ${ }^{0}$ & "Did you work for income during the past 12 months?" & Binary \\
\hline Internet access ${ }^{0}$ & $\begin{array}{l}\text { "Does anyone in your household have access to internet at } \\
\text { home?" }\end{array}$ & Binary \\
\hline Income ladder ${ }^{s}$ & $\begin{array}{l}\text { "Please imagine a ten-step ladder where on the bottom, the } \\
\text { first step, stand the poorest people and on the highest step, } \\
\text { the tenth, stand the richest. On which step of the ten is your } \\
\text { household today?" }\end{array}$ & $\begin{array}{l}\text { 10-point scale with } 1 \text { - "standing among the poorest" and } 10 \text { - } \\
\text { "among the richest". }\end{array}$ \\
\hline \multicolumn{3}{|l|}{ Political variables } \\
\hline Political activity ${ }^{0}$ & $\begin{array}{l}\text { "How likely are you to..." with four sections: "Attend lawful } \\
\text { demonstrations"; "Participate in strikes"; "Join a political party"; } \\
\text { "Sign petitions" }\end{array}$ & $\begin{array}{l}1 \text { - "have done", } 2 \text { - "might do", } 3 \text { - "would never do". The in- } \\
\text { dicator was constructed by combining the four parts of political } \\
\text { actions into one dummy ( } 1-0) \text { where } 1 \text { measures those who } \\
\text { have done any political activity. }\end{array}$ \\
\hline Democracy preference ${ }^{s}$ & $\begin{array}{l}\text { "With which one of the following statements do you agree } \\
\text { most?" }\end{array}$ & $\begin{array}{l}\text { Original: } 1 \text { - "Democracy is preferable to any other form of } \\
\text { political system"; } 2 \text { - "Under some circumstances, an authori- } \\
\text { tarian government may be preferable to a democratic one"; } 3 \text { - } \\
\text { "For people like me, it does not matter whether a government } \\
\text { is democratic or authoritarian". The variable was transformed } \\
\text { into a binary indicator of those who prefer democracy to any } \\
\text { other political system (answer 1) }\end{array}$ \\
\hline \multicolumn{3}{|l|}{ Social variables } \\
\hline Member in associations ${ }^{0}$ & $\begin{array}{l}\text { LiTS I: "Are you a member of a) a political party (excluded } \\
\text { in analysis) and b) other civic/voluntary organisation (club, } \\
\text { association)?" LiTS II: "Here is a list of voluntary organizations. } \\
\text { For each one, please indicate, whether you are an active } \\
\text { member, an inactive member, or not a member of that type of } \\
\text { organization" }\end{array}$ & Recoded into binary for 1 - "active member of any association" \\
\hline Trust (interpersonal) ${ }^{s}$ & $\begin{array}{l}\text { "Generally speaking, would you say that most people can be } \\
\text { trusted, or that you can't be too careful in dealing with people?" }\end{array}$ & 5-point scale: 1 - complete distrust to 5 - complete trust \\
\hline \multicolumn{3}{|c|}{ Health services individual-level variables } \\
\hline Health services usage ${ }^{0}$ & $\begin{array}{l}\text { "During the past } 12 \text { months have you personally received } \\
\text { medical treatment in the public health system?" }\end{array}$ & Binary \\
\hline $\begin{array}{l}\text { Out-of-pocket (OOP) payments } \\
\text { in health services }{ }^{s}\end{array}$ & $\begin{array}{l}\text { "In your opinion, how often is it necessary for people like you } \\
\text { to have to make unofficial payments/gifts in these situations? - } \\
\text { Receive medical treatment in the public health system" }\end{array}$ & 1 - never to 5 - always \\
\hline
\end{tabular}

All binary yes-no questions were coded into 1 - yes, 0 - no. Authors' comments in brackets. ${ }^{\circ}-$ objective indicators, ${ }^{s}-$ subjective $^{\prime}$ 
also reflects some relative inequalities. Generally, people who are better off economically are expected to have better health (19).

As a contextual economic proxy, GDP per capita at purchasing power parity (PPP) in 2005 US dollars from the World Bank was included. This is one of the most commonly used determinants of public health at the macro level. It was transformed into a natural logarithm (19), and was expected to positively influence self-rated health.

Political determinants encompass the wide sphere of institutions, policy knowledge and institutional trust, all of which have mostly indirect associations with health through health care, social security, and welfare support (8). While I could not control for the complex indirect links in this analysis, I controlled for political factors. "Political activity" (binary) was taken as an objective political measure at the individual level and it captures how active people are in political life. Preference for democracy was selected as the subjective political determinant and was coded into a binary indicator of those who preferred democracy to any other regime. Political indicators are deemed positively influential for health, though the links might not be necessarily direct.

When it comes to contextual political factors, a communist legacy of informal practices, lack of transparency, and presence of corruption has often determined the success of political and economic changes in CEE (20). Therefore, the Corruption Perceptions Index (CPI) was included in the models. The indicator was measured on a scale from 0 to 10 , where 0 indicated that the country is perceived as highly corrupt, and 10 - as most corruption-clean. CPI is expected to have a positive effect on health, hence less corrupt societies should perform better in terms of subjective health.

Social capital is one of the essential additions to the determinants of health. Its effects on health have been extensively analysed (21), however, there is still no consensus on what indicators serve as best proxies and what the relationship between social capital and health really is (22). All in all, four main domains of social capital are acknowledged: inter-personal and institutional participation, inter-personal and institutional trust. They are often narrowed down to two main components following the classic works of Putnam (23): membership in associations and trust, which were both included in this analysis. Membership in associations was transformed into a binary variable reflecting active membership in any of the associations. Interpersonal trust was measured on a five-point scale, with five reflecting complete trust. Social capital is most often assumed to affect health in a positive way.

At the macro level, same social capital aggregated indicators were included: membership in associations and trust in society, both represented the fraction of people in each country (from 0 to 1 ), who were members of associations, or had some or complete interpersonal trust. This was deemed to reflect overall contextual social cohesion in the society and to have a positive effect on health.

The final determinant in this paper is health care, which perhaps has the most direct effect on health. Health services usage at the individual level was included as an objective proxy of health care. The indicator was a binary variable of using the services in the past 12 months. To account for subjective evaluation of a healthcare system, an indicator reflecting the necessity to pay informal payments in health care was used. Arguably, the more often it is necessary to pay informally, the worse is the general evaluation of the public medical system. The indicator was coded on a five-point scale ranging from 1 - never to 5 - always. Both of these indicators are deemed to have a negative relation with self-rated health.

Contextual health care was measured as an average length of stay (ALOS) in days from WHO HfADb. ALOS is often a proxy for the overall functioning of healthcare system: normally the shorter it is, the more efficient the system tends to be. All summary statistics are reported in Table 3.

\section{Methods}

To analyse health and its determinants multi-level analysis (MLA) was used. I chose maximum likelihood estimation to have better comparability between the models. The analysis was performed in four steps. First, an empty model (M0) was estimated (Table 4). In the second step, the determinants of health at the micro-level within the fixed part of the regression were added, followed by individual-level interactions between the objectivesubjective pairs (M1-2). Third step included explanatory variables at the macro level (M3). In step four cross-level interactions were tested with random slopes (M5) and without (M4). All the other models tested are available on request. At each step I calculated the summary statistics of deviance and its difference (likelihood ratio test), the Schwarz's Bayesian Information Criterion (BIC), and variance explained by each model $\mathrm{R}^{2}$. All variables were grand mean centred, binary variables are left in their initial form (0-1).

There are two main levels in the dataset: individuals and countries. However, in order to control for the yearly changes between the two rounds of LiTS, three-level analysis was carried out: individuals (1st level), country-years ( 2 nd level) and countries (3rd level). A total of 27 countries were in LiTS pooled dataset. The two time points (2006 and 2010) nested in the countries created a total of 52 year-level units (Belarus and Tajikistan 2006 were excluded). All calculations were performed using Stata SE 14.

\section{RESULTS}

As explained in the section above, six final models are presented in Table 4. After running the empty model (M0), the intraclass correlation (ICC) was calculated, which was found to be $10.3 \%$ for the full sample, which provided a good reason for running MLA.

The overall fit of the models was improving from model M1 through to M5. The individual-level explanatory variables explained approximately $34 \%$ of variation in subjective health at the first level, $23 \%$ at the second and $36 \%$ at the third one (M2). Adding country-level indicators (M3) increased the explained variance at the year-country level to $87 \%$ and country level to $42 \%$. Each consecutive model had a better fit than the previous one according to the likelihood-ratio test. Model M5 had the best fit overall according to BIC and difference in deviance and is the final model in this analysis.

Demographic characteristics all had significant effect on health. Throughout all the models, the relationships were as expected and in line with other studies $(16,17)$. Age had a negative influence on self-rated health, while having a higher level of education positive. Men tended to report better health than women. Life satisfaction had a strong positive relation with subjective health. 
Table 3. Summary statistics of all variables used in the analysis $(N=46,546)$

\begin{tabular}{|c|c|c|c|c|}
\hline Variable & Mean & SD & Min & Max \\
\hline Subjective health & 3.375 & 0.976 & 1 & 5 \\
\hline Sex (1 = male) & 0.404 & 0.491 & 0 & 1 \\
\hline Age & 46.515 & 17.487 & 18 & 99 \\
\hline Low or no education & 0.250 & 0.433 & 0 & 1 \\
\hline Secondary education & 0.549 & 0.498 & 0 & 1 \\
\hline Higher education & 0.201 & 0.401 & 0 & 1 \\
\hline Life satisfaction & 3.088 & 1.120 & 1 & 5 \\
\hline Employment & 0.496 & 0.500 & 0 & 1 \\
\hline Income ladder & 4.305 & 1.703 & 1 & 10 \\
\hline Internet access & 0.289 & 0.453 & 0 & 1 \\
\hline Political activity & 0.179 & 0.383 & 0 & 1 \\
\hline Democracy preference & 0.547 & 0.498 & 0 & 1 \\
\hline Member in associations & 0.173 & 0.378 & 0 & 1 \\
\hline Trust & 2.802 & 1.149 & 1 & 5 \\
\hline Health services usage & 0.618 & 0.486 & 0 & 1 \\
\hline Out-of-pocket payments in health services & 2.343 & 1.395 & 1 & 5 \\
\hline GDP per capita (raw values) & $10,510.7$ & $5,940.3$ & $1,727.7$ & $24,819.9$ \\
\hline GDP per capita (logarithm) & 9.054 & 0.704 & 7.455 & 10.119 \\
\hline Corruption Perceptions Index & 3.522 & 1.258 & 1.7 & 6.6 \\
\hline Share of membership in association & 0.138 & 0.078 & 0.023 & 0.358 \\
\hline Trust in society & 0.326 & 0.099 & 0.081 & 0.559 \\
\hline Average length of stay & 9.541 & 2.182 & 5.7 & 15.05 \\
\hline
\end{tabular}

Besides demographics, all of the individual-level indicators remained relatively stable throughout the models. Economic indicators at the individual level influenced health in an expected way (M1): all three indicators were positively related, and were significant throughout the models (both objective and subjective indicators). In model M2 several interaction terms between the objective and subjective dimensions were added. While the overall effect on self-rated health was positive for both employment and income ladder evaluation, there was a negative interaction between the two. In other words, with higher evaluation of income, the effect of employment on subjective health was decreasing, and vice versa: being unemployed increased the effect of income evaluation.

Among the political indicators at the individual level, preference for democracy had a positive relation with subjective health throughout the models, though the coefficients were very small. At the same time, political activity was insignificant for subjective health. Social capital also produced consistent findings across the models: membership in associations was not significant in any of the models, while trust had a significant positive effect throughout. This confirmed the prior findings that social capital might influence health, but only the subjective component of it.

Health care usage and evaluation of informal practices in health care both had expected signs (negative) and were significant. However, I found that as soon as the interaction between the two health services indicators was added (M2), evaluation of out-of-pocket payment (OOP) became insignificant. This means that the effect of OOP evaluation was mediated through the health services usage. On the one hand, the effect of OOP on health was not significant for those who had not used health care services. On the other, those who had used health care services evaluated their health worse overall (compared to those who did not). Furthermore, the negative effect of using medical services on self-rated health is higher in this group for those who consider they have to pay OOP more often.

Models M3 though to M5 added the country-level variables to the analysis. CPI had an unexpected negative relation to subjective health, though the coefficient was rather small. Both contextual social indicators were significant positive predictors of individual self-rated health; hence, people in societies with stronger overall social cohesion tended to evaluate health better. ALOS had a negative effect on self-rated health, hence countries where hospital stays were longer had a lower average health evaluation.

GDP was found to have a significant positive effect on self-rated health at first (M3). However, after adding the cross-level interaction between two economic variables, employment and GDP, findings became more complex (M4-5). Once the interaction was added (M4), GDP becomes insignificant: there was no significant effect of GDP on health for unemployed. However, the interaction itself was significant, which could mean that it was not GDP per se that influenced health evaluation, but GDP in combination with the individual-level employment. Those who were employed and living in higher income countries tended to evaluate health best of the sample but being unemployed in a higher-income country was still better than in lower-income country for individual self-rated health. Model M5 clarified the relationship further: introducing a random slope for employment resulted in insignificant GDP and cross-level interaction, but significant random slope. In other words, there might have been a different relationship between employment and self-rated health in different countries. 
Table 4. Multi-level regression. DV: Subjective health (1-5) $(N=46,546)$

\begin{tabular}{|c|c|c|c|c|c|c|}
\hline & MO & M1 & M2 & M3 & M4 & M5 \\
\hline \multicolumn{7}{|l|}{ Fixed part } \\
\hline Intercept & $3.383^{\star \star *}$ & $3.173^{\star * *}$ & $3.181^{* * *}$ & $3.179^{\star * *}$ & $3.179^{* * *}$ & $3.183^{* * *}$ \\
\hline \multicolumn{7}{|l|}{ Demographic variables } \\
\hline $\operatorname{Sex}(1=\text { male })^{0}$ & & $0.101^{* * *}$ & $0.102^{* * *}$ & $0.102^{\star * *}$ & $0.102^{\star \star *}$ & $0.104^{* * *}$ \\
\hline Age $^{0}$ & & $-0.022^{\star * \star}$ & $-0.022^{* * *}$ & $-0.022^{* * *}$ & $-0.022^{* * *}$ & $-0.022^{* * *}$ \\
\hline Secondary education ${ }^{\circ}$ & & $0.145^{* \star *}$ & $0.144^{* * *}$ & $0.144^{* * *}$ & $0.144^{* * *}$ & $0.141^{* * *}$ \\
\hline Higher education ${ }^{\circ}$ & & $0.26^{\star \star \star}$ & $0.262^{* * *}$ & $0.262^{* * *}$ & $0.263^{\star \star *}$ & $0.261^{\star \star *}$ \\
\hline Life satisfaction ${ }^{s}$ & & $0.102^{* \star *}$ & $0.101^{* * *}$ & $0.101^{* * *}$ & $0.102^{* * *}$ & $0.102^{* * *}$ \\
\hline \multicolumn{7}{|l|}{ Economic individual-level variables } \\
\hline Employment $^{0}$ & & $0.149^{* * *}$ & $0.149^{* * *}$ & $0.149^{* \star *}$ & $0.149^{* * *}$ & $0.149^{* * *}$ \\
\hline Income ladder ${ }^{s}$ & & $0.066^{* * *}$ & $0.077^{\star \star *}$ & $0.077^{\star \star *}$ & $0.077^{* \star *}$ & $0.078^{* * *}$ \\
\hline Internet access ${ }^{0}$ & & $0.065^{\star * *}$ & $0.067^{\star * *}$ & $0.065^{* * *}$ & $0.062^{\star * *}$ & $0.061^{* * *}$ \\
\hline \multicolumn{7}{|l|}{ Political individual-level variables } \\
\hline Political activity ${ }^{0}$ & & 0.019 & 0.019 & 0.019 & 0.018 & 0.015 \\
\hline Democracy preference ${ }^{s}$ & & $0.057^{\star * *}$ & $0.057^{\star * *}$ & $0.056^{* * *}$ & $0.057^{\star \star *}$ & $0.056^{\star \star *}$ \\
\hline \multicolumn{7}{|l|}{ Social individual-level variables } \\
\hline Member in associations ${ }^{0}$ & & -0.011 & -0.01 & -0.012 & -0.012 & -0.01 \\
\hline Trust $^{\mathrm{s}}$ & & $0.032^{* * *}$ & $0.032^{* * *}$ & $0.032^{* * *}$ & $0.032^{* * *}$ & $0.032^{* * *}$ \\
\hline \multicolumn{7}{|l|}{ Health services individual-level variables } \\
\hline Health services usage ${ }^{\circ}$ & & $-0.141^{* * *}$ & $-0.144^{* * *}$ & $-0.144^{* * *}$ & $-0.144^{* * *}$ & $-0.143^{* * *}$ \\
\hline Out-of-pocket payments in health services ${ }^{s}$ & & $-0.019^{* * *}$ & -0.007 & -0.007 & -0.006 & -0.007 \\
\hline \multicolumn{7}{|l|}{ Objective-subjective interactions } \\
\hline Employment x Income ladder & & & $-0.022^{* \star *}$ & $-0.022^{* * *}$ & $-0.023^{\star \star \star}$ & $-0.026^{\star \star *}$ \\
\hline HS usage $x$ OOP in HS & & & $-0.019^{\star * *}$ & $-0.019^{* * *}$ & $-0.019^{* * *}$ & $-0.018^{\star * *}$ \\
\hline \multicolumn{7}{|l|}{ Country-level variables } \\
\hline GDP per capita (logarithm) ${ }^{\circ}$ & & & & $0.110^{*}$ & 0.094 & 0.104 \\
\hline Corruption Perceptions Index ${ }^{0}$ & & & & $-0.065^{\star}$ & $-0.065^{*}$ & $-0.066^{*}$ \\
\hline Share of membership in associations ${ }^{0}$ & & & & $0.012^{* * *}$ & $0.012^{* * *}$ & $0.012^{* * *}$ \\
\hline Trust in societys & & & & $0.005^{* *}$ & $0.005^{* *}$ & $0.005^{\star *}$ \\
\hline Average length of stay ${ }^{\circ}$ & & & & $-0.07^{* \star *}$ & $-0.07^{* * *}$ & $-0.066^{* * *}$ \\
\hline \multicolumn{7}{|l|}{ Cross-level interaction } \\
\hline Employment x GDP & & & & & $0.0328^{* *}$ & 0.01 \\
\hline \multicolumn{7}{|l|}{ Random part } \\
\hline Variance (country) & $0.054^{* \star *}$ & $0.034^{\star * *}$ & $0.034^{* * *}$ & $0.031^{* * *}$ & $0.032^{\star \star *}$ & $0.031^{* * *}$ \\
\hline Variance (year-country) & $0.028^{* * *}$ & $0.022^{* * *}$ & $0.022^{* * *}$ & $0.004^{* * *}$ & $0.004^{* * *}$ & $0.003^{* * *}$ \\
\hline Variance (residual) & $0.87^{* * *}$ & $0.579^{* \star *}$ & $0.579^{* * *}$ & $0.579^{\star \star *}$ & $0.579^{\star * *}$ & $0.577^{\star \star *}$ \\
\hline Variance (employment) & & & & & & $0.008^{* * *}$ \\
\hline \multicolumn{7}{|l|}{ Summary statistics and model fit } \\
\hline Deviance & $125,962.8$ & $106,905.4$ & 106,866 & 106,816 & 106,806 & $106,694.6$ \\
\hline $\mathrm{BIC}$ & $120,767.2$ & 102,755 & $102,735.4$ & $102,741.6$ & $102,740.2$ & $102,655.3$ \\
\hline$R_{1}^{2}$ (individual) & & 0.337 & 0.337 & 0.337 & 0.337 & 0.339 \\
\hline$R_{2}^{2}$ (year-country) & & 0.215 & 0.229 & 0.873 & 0.873 & 0.873 \\
\hline$R_{3}^{2}$ (country) & & 0.359 & 0.359 & 0.416 & 0.413 & 0.41 \\
\hline
\end{tabular}

${ }^{*} \mathrm{p}<0.05,{ }^{* *} \mathrm{p}<0.01,{ }^{* \star *} \mathrm{p}<0.001$.

Intraclass correlations: ICC $=0.085 ;$ ICC $=0.054$ (full dataset: 0.1 and 0.076 , respectively).

$R_{1}^{2}, R_{2}^{2}, R_{3}^{2}$ - coefficcients of determination explained variance at each level, calculated using Raudenbush and Bryk method (48). This is an approximate and is taken with caution, particularly for the random slopes model (M5).

${ }^{\circ}$ - objective; ${ }^{\mathrm{s}}$ - subjective indicator; HS - health services; OOP - out-of-pocket payments 


\section{DISCUSSION}

The aim of this study was to explore the self-rated health determination process in the countries of CEE and to study both the objective and subjective indicators as health determinants. The framework was dictated by existing research $(10,15)$ and provided a more encompassing approach to health determinants. The main objective was not to identify one main factor to account for health changes but to explore the whole picture.

Many of the determinants were found to have the anticipated effects on self-rated health but several were unexpected. The demographic indicators (sex, age, education), all had the expected effects on health in line with previous studies $(16,17)$, and are necessary controls.

Among the political and social indicators, only the subjective concepts had an effect on health. This could be related to the similar evaluative nature of the indicators in question: democracy preference, trust and self-rated health are all subjective. Another explanation could suggest a stronger psycho-social link between the political and social determinants and health as argued by others (24). The effect of trust rather than membership in associations on health supports another study (25).

Both contextual social capital indicators had an effect on health. Therefore, the overall social climate in the country is an important influence for subjective health. This finding are in contrast to that of Poortinga (26), who finds no effect of the social capital context, but a more complex cross-level interaction effect present (no such interactions were found significant in our analysis). At the same time, Kim et al. (25) find that unequal societies with weaker egalitarian safety nets show stronger relationship between social capital and health, and this could explain our finding: many of the CEE countries can indeed be considered to possess weaker formal safety nets, hence social capital steps in instead.

Surprisingly, corruption had a negative relation with health. When one looks at the CPI for the CEE countries, the best performer in the set is Estonia, which also scores at the bottom for self-rated health. At the same time, countries in the south with Mediterranean-like lifestyles (Albania, Montenegro) do not score highly on CPI, but have some of the highest health scores (Albania, Macedonia and Montenegro topping the list). The same goes to the countries of Central Asia: Uzbekistan, Kyrgizstan and Tajikistan, which score lowest on CPI, but report high self-rated health. On the one hand, this could imply that another political indicator has to be controlled for when analysing health in this particular set of countries. On the other hand, the analysis would also benefit from lifestyles and environment being controlled for. However, one of the limitations this research inevitably met was the data limitation for certain variables. Hence, marital status, lifestyle, environment and income inequality had to be excluded. Present results, however, might signal the importance of including these factors, and they will be considered in the future research.

When it came to the economic individual effects on health, both objective and subjective economic indicators mattered for subjective health at the individual level in agreement with other researchers (27). The relationship was further complicated by the presence of interaction between objective and subjective indicators. While the exact relationship could be different depending on the choice of indicators (in this analysis the interaction was negative), it is clear that the objective-subjective variables are not independent in the way they influence health.

In relation to the economic context I did not find a strong effect of GDP on subjective individual-level health, in line with other research (28). In fact, the analysis showed that the relationship between subjective health and economic indicators (employment in this case) was different in different countries of CEE. Overall, GDP itself might be unimportant. Perhaps welfare state support is, but it in turn could depend on the economic affluence of each country.

The relationship between health services usage and health was negative, as supported by other research (29). There was also an interaction present which cancelled out the individual effect of OOP evaluation, which meant the combination of both objective and subjective health services had an effect on self-rated health. Health services efficiency measured by average length of stay had a negative effect on subjective health in CEE. This finding is in accord with other studies (30), and once again confirms the still present importance of the contextual health care, even when the individual-level characteristics are controlled for.

All in all, I find expected results for most of the determinants. Besides, there are strong effects of social and health care contexts, but no such relationships are found for economic or political affluence. However, it is important to pay attention to the objective-subjective nature of the indicators and return to the second goal of this article.

I find that objective and subjective indicators influence health differently within the different domains (economic, political, social and medical). While I do find that subjective rather than objective political and social indicators influence subjective health as is suggested by Ostrove et al. (12), findings for other domains suggest a more complex relationship of interrelation. These results are in accord with Miething's findings (31) that subjective and objective determinants are interrelated. Regardless of the exact relationship, our results suggest that there is a clear difference between the two dimensions of determinants of health in CEE: objective and subjective, which should not be ignored.

\section{CONCLUSIONS}

This study has attempted to investigate the factors which influence subjective health in Central and Eastern Europe using a wide range of objective and subjective determinants in a rigorous multilevel design. Very often studies concentrate on a limited number of indicators, without considering the wider picture. This study incorporates several sets of determinants which were systematically chosen for the analysis among those that have previously been shown to influence health. The findings in this paper suggest that this systematic approach can pay off and could be a way forward. Several conclusions can be made about health determinants in CEE.

First, I found that objective and subjective indicators do not influence subjective health in a similar fashion in different domains (economic, political, social and medical) in CEE. I cannot argue that subjective determinants are more linked to subjective health as the findings suggest that both objective and subjective factors are important for self-rated health, in different ways. It is clear that the relationships are different between the two dimensions. While it also depends on the exact variables that are taken, 
it is advisable to select objective proxies for objective concepts and vice versa.

It is also recommended to use both subjective and objective determinants wherever possible, as I find they might have different influences on health, as well as some of them could interact with each other (health care and economic indicators in this study). The findings of the current study imply that the practice of convenience-selection of indicators could create bias and should be avoided.

Second, contextual-level prosperity is not an important determinant of subjective health in CEE countries. This means that the CEE countries differ in the way individual-level economic circumstances influence health. At the same time, social and healthcare contexts are significant. Therefore, country-differences are large in CEE, particularly in terms of social capital environment, efficiency of healthcare system and individual economic prosperity, and these have a strong effect on individual self-rated health.

All in all, is there the main culprit for health in the countries of the CEE region? The answer is, unfortunately, neither simple nor straightforward. The determinants are complex and interrelated. It is evident that the whole spectrum of societal forces and individual characteristics affect health. It is important to look at the bigger picture, at the whole system, when dealing with general health determinants, both in CEE and elsewhere. Health and the factors influencing it are embedded in an overall environment and individuals' lives, and discarding them might lead to bias. Developing and applying a systematic and encompassing approach to studying health might be of utmost importance. This could also be essential for public health workers who strive to find a way to improve health. In order to get the answers, the complexity of the world has to be considered, understood and structured.

\section{Acknowledgement}

I am grateful to the Bremen International Graduate School of Social Science for the support during the initial stages of this research. My special gratitude also goes to all the colleagues of the Research Group on Welfare and Life Course at the Department of Sociology, Uppsala University, who have commented and discussed the draft of this paper on several occasions.

\section{Conflict of Interests}

None declared

\section{REFERENCES}

1. Bobak M, Pikhart H, Rose R, Hertzman C, Marmot M. Socioeconomic factors, material inequalities, and perceived control in self-rated health: cross-sectional data from seven post-communist countries. Soc Sci Med. 2000;51(9):1343-50.

2. Brainerd E, Cutler DM. Autopsy on an empire: understanding mortality in Russia and the former Soviet Union. J Econ Perspect. 2005;19(1):107-30.

3. Bobak M, Malyutina S, Horvat P, Pajak A, Tamosiunas A, Kubinova R, et al. Alcohol, drinking pattern and all-cause, cardiovascular and alcoholrelated mortality in Eastern Europe. Eur J Epidemiol. 2016 Jan;31(1):21-30.

4. Berger MC, Messer J. Public financing of health expenditures, insurance, and health outcomes. Appl Econ. 2002;34(17):2105-13.

5. WHO, Commission on Social Determinants of Health. Closing the gap in a generation: health equity through action on the social determinants of health. Final Report of the Commission on Social Determinants of Health [Internet]. Geneva: WHO; 2008 [cited 2019 May 28]. Available from: http://whqlibdoc.who.int/publications/2008/9789241563703_eng. pdf.
6. Inglehart R, Foa R, Peterson C, Welzel C. Development, freedom, and rising happiness: a global perspective (1981-2007). Perspect Psychol Sci. 2008;3(4):264-85.

7. Szreter S. The Population health approach in historical perspective. Am J Public Health. 2003 Mar;93(3):421-31.

8. Eikemo TA, Bambra C, Judge K, Ringdal K. Welfare state regimes and differences in self-perceived health in Europe: a multilevel analysis. Soc Sci Med. 2008;66(11):2281-95.

9. Diez-Roux AV. Multilevel analysis in public health research. Annu Rev Public Health. 2000;21:171-92.

10. Dahlgren G, Whitehead M. Policies and strategies to promote social equity in health. Copenhagen: WHO Regional Office for Europe; 1991.

11. Cummins RA. Objective and subjective quality of life: an interactive model. Soc Indic Res. 2000;52(1):55-72.

12. Ostrove JM, Adler NE, Kuppermann M, Washington AE. Objective and subjective assessments of socioeconomic status and their relationship to self-rated health in an ethnically diverse sample of pregnant women. Health Psychol. 2000;19(6):613-8.

13. Subramanian SV, Belli P, Kawachi I. The macroeconomic determinants of health. Annu Rev Public Health. 2002;23:287-302.

14. Dolan CV. Factor analysis of variables with 2, 3, 5 and 7 response categories: A comparison of categorical variable estimators using simulated data. Br J Math Stat Psychol. 1994;47(2):309-26.

15. Starfield B. Basic concepts in population health and health care. J Epidemiol Community Health. 2001;55(7):452-4.

16. Braveman P, Barclay C. Health disparities beginning in childhood: a life-course perspective. Pediatrics. 2009 Nov;124 Suppl 3:S163-75.

17. Hill TD, Needham BL. Gender-specific trends in educational attainment and self-rated health, 1972-2002. Am J Public Health. 2006;96(7):1288-92.

18. Sala-i-Martin X. On the health-poverty trap. In: López-Casasnovas G, Rivera B, Currais L, editors. Health and economic growth: findings and policy implications. Cambridge (MA): MIT Press; 2005. p. 95-114.

19. Deaton A. Global patterns of income and health: facts, interpretations, and policies [Internet]. Cambridge (MA): National Bureau of Economic Research; 2006 [cited 2019 May 28]. Available from: http://www.nber. org/papers/w12735.

20. Ledeneva A. Corruption in postcommunist societies in Europe: a reexamination. Perspect Eur Polit Soc. 2009;10(1):69-86.

21. Kawachi I, Subramanian SV, Kim D. Social capital and health. New York: Springer; 2008.

22. Adams J, White M. Evidence concerning social capital and health inequalities is still lacking. J Public Health Med. 2003;25(2):184-5.

23. Putnam RD. Bowling alone: America's declining social capital. J Democr. 1995;6(1):65-78.

24. Wilkinson RG. Unhealthy societies: the afflictions of inequality. London: Routledge; 1996.

25. Kim D, Subramanian SV, Kawachi I. Social capital and physical health: a systematic review of the literature. In: Kawachi I, Subramanian SV, Kim D, editors. Social capital and health. New York: Springer; 2008. p. 139-90.

26. Poortinga W. Social capital: An individual or collective resource for health? Soc Sci Med. 2006;62(2):292-302.

27. Lantz PM, Pritchard A. Socioeconomic indicators that matter for population health. Prev Chronic Dis [Internet]. 2010 Jul [cited 2019 May 28];7(4):A74. Available from: https://www.cdc.gov/pcd/issues/2010/jul/ pdf/09_0246.pdf

28. Jen MH, Jones K, Johnston R. Global variations in health: Evaluating Wilkinson's income inequality hypothesis using the World Values Survey. Soc Sci Med. 2009;68(4):643-53.

29. Filipkowski KB, Smyth JM, Rutchick AM, Santuzzi AM, Adya M, Petrie $\mathrm{KJ}$, et al. Do healthy people worry? Modern health worries, subjective health complaints, perceived health, and health care utilization. Int $\mathrm{J}$ Behav Med. 2010 Sep;17(3):182-8.

30. Borisova LV. Health care systems as determinants of health outcomes in transition countries: Developing classification. Soc Theory Health. 2011;9(4):326-54

31. Miething A. The Relevance of objective and subjective social position for self-rated health: a combined approach for the Swedish context. Soc Indic Res. 2013;111(1):161-73.

32. Raudenbush SW, Bryk AS. Hierarchical linear models: applications and data analysis methods. Thousand Oaks: Sage Publications; 2002. 